\title{
IoT Based LPG Leakage Detection and Booking System with Customer SMS Alerts
}

\author{
M Anusha ${ }^{1}$ | V Nagesh ${ }^{1}$ | B Venkata Sai ${ }^{1} \mid$ K Srikanth ${ }^{1}$ | Rupalin Nanda ${ }^{2}$
}

${ }^{1}$ UG Students, Department of Electronics and Communication Engineering, Godavari Institute of Engineering and Technology (A), Rajahmundry, Andhra Pradesh, India.

${ }^{2}$ Assistant Professor, Department of Electronics and Communication Engineering, Godavari Institute of Engineering and Technology (A), Rajahmundry, Andhra Pradesh, India.

\section{To Cite this Article}

M Anusha, V Nagesh, B Venkata Sai, K Srikanth and Rupalin Nanda, "IoT Based LPG Leakage Detection and Booking System with Customer SMS Alerts", International Journal for Modern Trends in Science and Technology, Vol. 06, Issue 05, May 2020, pp.:01-05; https://doi.org/10.46501/IJMTST060501

\section{Article Info}

Received on 30-March-2020, Revised on 19-April-2020, Accepted on 23-April-2020, Published on 28-April-2020.

\section{ABSTRACT}

Liquefied petroleum fuel (LPG) is the most vital phase of every day human life, however the protection of human existence is required for the gasoline explosion. This methodology is used to shield human life. In this, the MQ2 sensor is used to realize fuel leaks in the home. If the fuel leak is detected automatically, it will ship an SMS to the user. Wifi is one of the most used networks in the world. It additionally affords the computerized reserve characteristic of LPG gasoline when the proprietor is busy and measures the non-stop weight of the LPG cylinder the use of a load cell. An AWS server is used to join the patron to the administrator and robotically replace the reservation data on the server. This work helps the business enterprise to especially point out the gasoline leak and helps each clients and the corporation to mechanically e book the fuel the use of the IOT technique.

KEYWORDS: GSM Modem, Gas Sensor, Load Cell, AWS server

Copyright (C) 2014-2020 International Journal for Modern Trends in Science and Technology, All rights reserved.

DOI: https://doi.org/10.46501/IJMTST060501

\section{INTRODUCTION}

There are about 89\% householder's uses LPG cylinders in India. The Several requirements have been carried out for the fuel leakage detection system. The current structures offers an alarm machine which is on the whole supposed to discover an Gas leakage in the house and industrial premises The goal of the proposed machine is to always measure the weight of the cylinder and as quickly as it reaches the minimal threshold it will routinely sends an SMS alert to the consumer as nicely as Authorized LPG agent so that they can act accordingly. This machine additionally designed to realize LPG gases such as propane and butane. The allowed degree for butane is 600ppm above which it is regarded to be of excessive degree and poses a danger. The threshold stage of weight of the cylinder is used for automated cylinder booking. The foremost intention of this venture is to screen for liquid petroleum gasoline (LPG) leakage to keep away from primary hearth accidents and additionally facilitating protection precautions the place protection has been an essential trouble and automated cylinder reserving except human intervention. The gadget detects the leakage of the LPG the usage of gasoline sensor and signals the customer about the fuel leakage by way of sending

1 International Journal for Modern Trends in Science and Technology 
SMS. The gadget measure the weight of cylinder by using the use of weight sensor and show corresponding weight in LPG display. The proposed gadget makes use of the GSM Modem to alert the man or woman about the gasoline leakage by way of SMS and repute of automated cylinder booking. When the machine identifies that LPG attention in the air reaches the designated degree then it alert the purchaser via sending SMS to registered cellular smartphone and alert the humans at domestic via activating the alarm which consists of Buzzer concurrently and additionally show the identical message on LCD to take the fundamental motion and change on the exhaust fan or opening home windows to limit the fuel attention in the air.

\section{Literature SURVEY}

In the year 2011, A. MAHALINGAM, R. T. NAAYAGI,1, N. E. MASTORAKIS, "Design and Implementation of an Economic Gas Leakage Detector", This project developed system to detect the gas leakage and providing immediate alarm or intimation to the user.

Later in 2013, few people developed the design proposed for home safety. This system detects the leakage of the LPG and alerts the consumer about the leak by buzzer. This project was developed using microcontroller ARM version 7 processor and simulated using Keil software.

In the year 2014, Hitendra Rawat, Ashish Kushwah, Khyati Asthana, Akanksha Shivhare, designed a system, They provided security issues against thieves, leakage and fire accidents. In those cases their system sends SMS to the emergency number provided to it.

In the proposed system we have designed "LPG gas monitoring and automatic cylinder booking with alert system". These report focus on detection of economic fuels like petroleum, liquid petroleum gas, alcohol..etc., and alert the surrounding people about the leakage through SMS. It also sense surrounding temperature, so that no fire accidents occurs.

The one more important feature is automatic cylinder booking by noticing the current expenditure of LPG gas in our daily life. These projects alert the user by sending message to mobile through SMS in three conditions. They are

> When LPG gas weight reaches to maximum threshold value.

$>$ When the LPG gas exceed its peak value.

$>$ When the temperature exceed more than room temperature.
These project gives alert message by buzzing the buzzer and trough SMS to the house holders. We also provide automatic doors and windows opening, so that the compressed gas can spread in to air freely. Hence a fire accident does not occurs.

\section{SySTEM ARChITECTURE}

This proposed method consists of gas leakage detection system, weight measurement module, microcontroller, GSM module and alert system. The main basic Arduino atmega $328 \mathrm{p}$ micro controller requires the power supply ranging from 7-12 volts. The board can operate on at 7-12 volts. If voltage $<7 \mathrm{~V}$ then board becomes unstable. If voltage $>12 \mathrm{~V}$ then board get damaged.

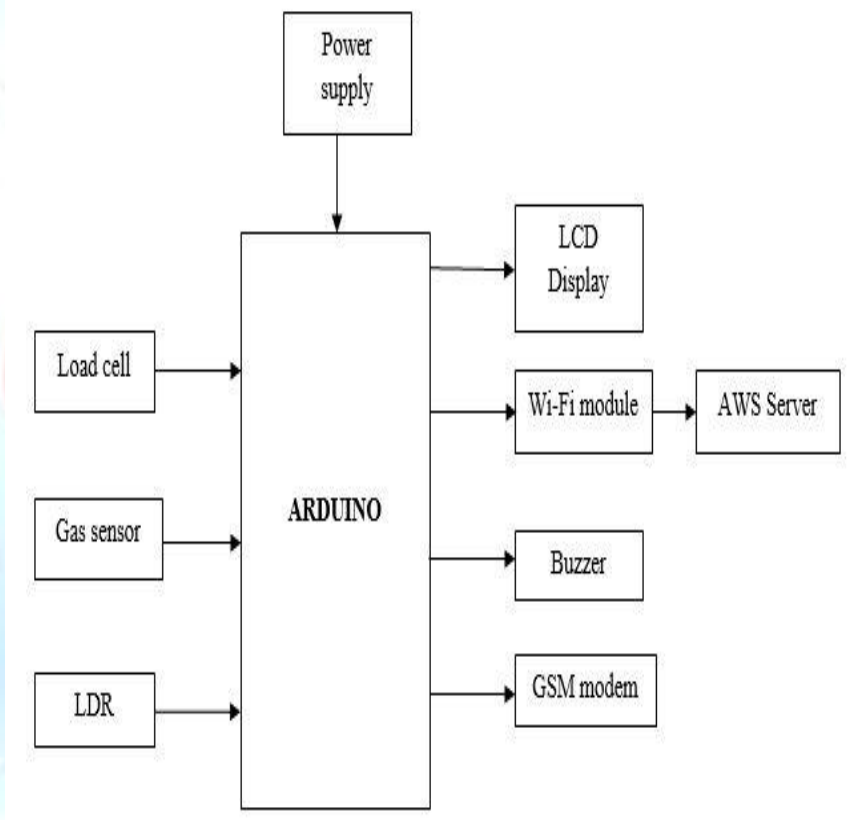

Fig. 1 Architecture of gas leakage detection system

The Main platform we are using to build the project is Arduino atmega 328p which provides us the flexibility to write the code effectively in convenient way and also it will provides us features like Inexpensive, Cross platform, Simpler and clear programming environment, Open source and extensible software, Easy for beginners. And simply connect it to a computer with a USB cable or power it with a AC to-DC adapter or battery to get started. The other main component we are using in our project is use of Load cell. A load cell is a transducer that is used to convert a force into electrical signal, which is used to measure of a LPG gas cylinder weight so that we can expect and alert the user with in how many days the cylinder is about to empty. There are different Load cells available in the market with different weight 
measurement capabilities. The type of load cell used in this project is straingauge load cell

The Gas Sensor is also one of the components used to detect the leakage of the LPG Gas (Methane \&Propane) which converts one form of the signal into other form to avoid the noise of alcohol and cooking fumes and cigarette smoke. The MQ-4 can detect natural gas concentrations from 200 to 10000 ppm.High sensitivity to $\mathrm{CH} 4$, Natural gas. MQ 4 has Fast response, Stable and long life. The LM35 series is a precision IC temperature devices with an output voltage linearlyproportional to the Centigrade temperature. LCD (Liquid Crystal Display) is used to show the output of the results of Different sensor values and various results to show of size about 32 ASCII character in 2 lines commonly used one is $16 \times 2$ LCD modules. We are using GSM Modem to alert the user by sending SMS(Short Message Service) about Gas Leakage and LPG Gas Completion Status.GSM (Global System for Mobile communication) is a digital mobile telephony system that is widely used in England and different parts of the world. GSM uses of time division multiple access (TDMA) and is the most widely used of the technologies (TDMA, GSM, and CDMA). GSM digitizes and syncs data, then sends it to a channel with two other streams of user data, each in its own time slot. It operates at either the $800 \mathrm{MHz}$ or $1800 \mathrm{MHz}$ frequency band.

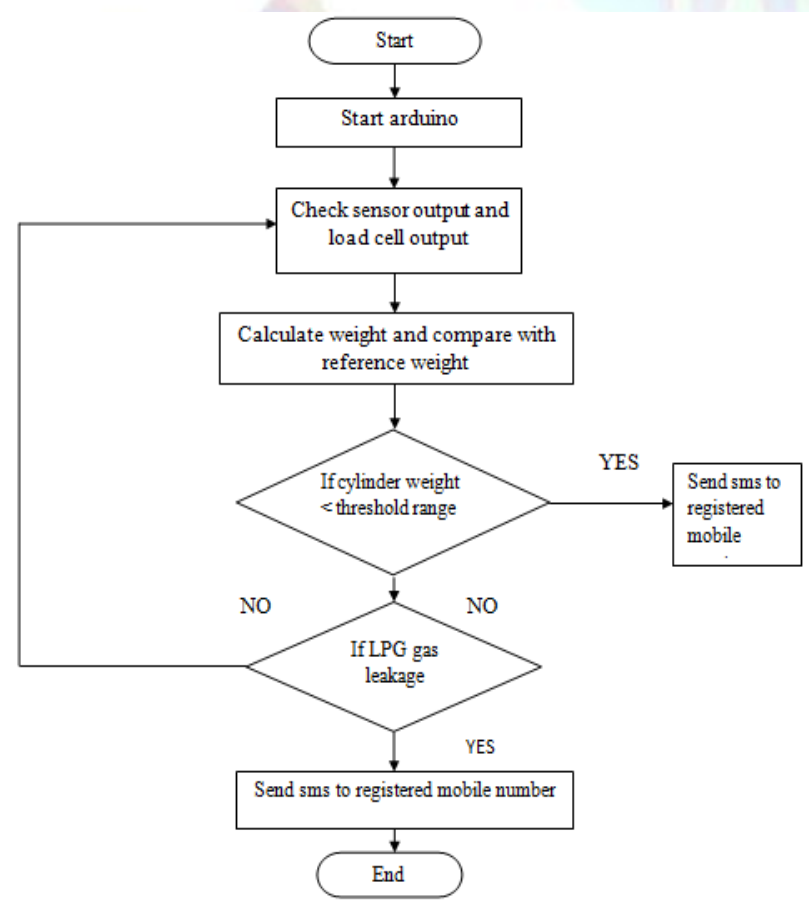

Figure 2 :Flow diagram of the activites of the gas leakage detection system.
Figure 2 shows the flow chart for detecting the gas leakage. The microcontroller is the only component that requires instruction to be written and run it to perform the desire roles. Assembly language is used in the programming of the microcontroller. Figure illustrates the flowchart of procedure of programming the microcontroller to achieve the desire function.

After the design exercise, various components described earlier in the design consideration section were sourced. The developed GSM-based gas leakage detection and alert system was then implemented using the obtained circuit diagram from the design.

\section{DESCRIPTION OF HARDWARE COMPONENTS}

The major components used in the circuit is, GSM Module: GSM Module GSM (Global System for Mobile) / GPRS (General Packet Radio Service) TTL modem s SIM900 quad-band GSM / GPRS device, works on frequencies $850 \mathrm{MHZ}, 900 \mathrm{HZ}$, $800 \mathrm{MHZ}$ and $1900 \mathrm{HZ}$. It is very compact in size and easy to use as plug in GSM Modem. The Modem is designed with $3 \mathrm{~V} 3$ and $5 \mathrm{~V}$ DC TTL interfacing circuitry, which allows User to directly interface with $5 \mathrm{~V}$ microcontrollers (PIC, AVR, Arduino, 8051, etc.) as well as 3V3 Microcontrollers (ARM, ARM Cortex XX, etc.).

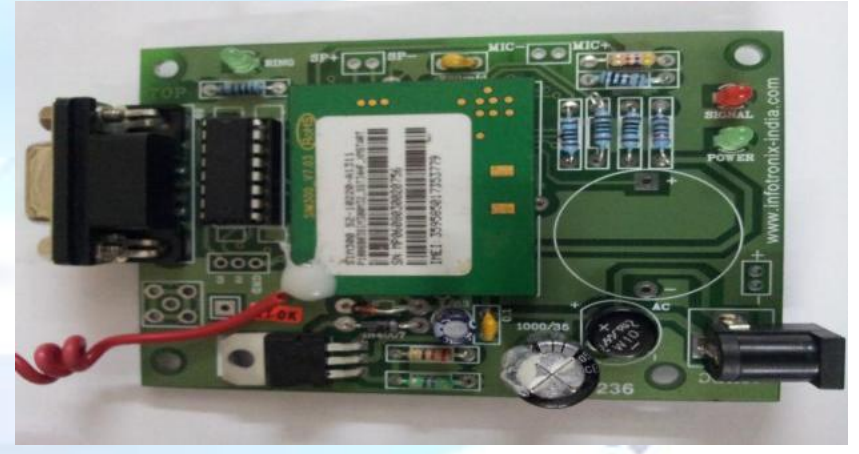

Fig 4: GSM SIM800 Module

Piezoelectric buzzer: Buzzer is an audio signaling device. The typical uses of buzzers are for alarms, timers and confirmation of user input such as a mouse click or keystroke. The project used an electronic type of buzzer which is a piezoelectric element that driven by an micro-controller signals. Peizo buzzer is based on the inverse principle of peizo electricity discover in 1880 by Jacques and Pierre Curie. It is the phenomenon of generating electricity when mechanical pressure is applied to the certain materials and the vice versa. such materials called Piezoelectric materials. When an alternating electric field subjected to the material 
they stretch or compress accordance with the frequency of the signal thereby producing sound.

LCD Display: LCD stands for Liquid Crystal Display.. They have become very common with industry by clearly replacing the use of Cathode Ray Tubes (CRT). CRT consumes more power than LCD and also bigger and heavier. We all know about LCD"s, but no one knows the exact working of it. LCD is finding wide spread use replacing LEDs (seven segments or other multi segment LEDs) due to the following reasons:

$>$ The declining prices of LCDs.

> The ability to display numbers, characters and graphics related data. This is in contrast to LEDs, which are limited to numbers and a few characters.

$>$ Incorporation of a controller into the LCD, thereby making the CPU to keep displaying the data.

$>$ Ease to program for characters, strings and graphics related data.

These are specialized for being used with the microcontrollers, which makes that they cannot be activated by standard IC circuits. They are used for writing different messages on a miniature LCD.

Wifi Module: The ESP8266 arduino compatible module is a low-cost Wi-Fi chip with full TCP/IP capability, and the amazing thing is that this little board has a MCU (Micro Controller Unit) integrated which gives the possibility to control I/O digital pins via simple and almost pseudo-code like programming language. This device is produced by Shanghai-based Chinese manufacturer, Espress if Systems.

Methane Gas Sensor: Sensitive material of MQ-2 gas sensor is $\mathrm{SnO}$, which with lower conductivity in clean air. When the target combustible gas exist, the sensor's conductivity is higher along with the gas concentration rising. Please use simple electro circuit, Convert change of conductivity to correspond output signal of gas concentration. MQ-2 gas sensor has high sensitivity to Methane, also to Propane and Butane. The sensor could be used to detect different combustible gas, especially Methane, it is with low cost and suitable for different application.

Load Cell Sensor: Load cell sensor is device used to measure weight .It is a passive transducer or sensor which converts applied force into electrical signals. They are also referred to as "Load transducers". We are using Load cell sensor for measuring weight of cylinder .Load cell sensor continuously measure weight of cylinder if weight of cylinder is below particular level then it will send sensor value to arduino board com 3 port from where we fetch the data come from sensor and using TextLocal API we automatically book gas cylinder using number store in memory and also send message to owner. For a $120 \Omega$ gauge, this is a change of only $0.12 \Omega .0 .12 \Omega$ is a very small change, and, for most devices, couldn't actually be detected, let So we are going to need another device HX711 which is a amplifier and this amplifier able accurately measure super small changes in resistance.

\section{Results AND Discussions}

In IOT based automated LPG leakage detection and booking system with customer sms alerts MQ-2 gas sensor, $5 \mathrm{~kg}$ load cell (for prototype) as input devices and piezo electric buzzer, $16^{*} 2 \mathrm{LCD}$ Display and GSM module used as output devices

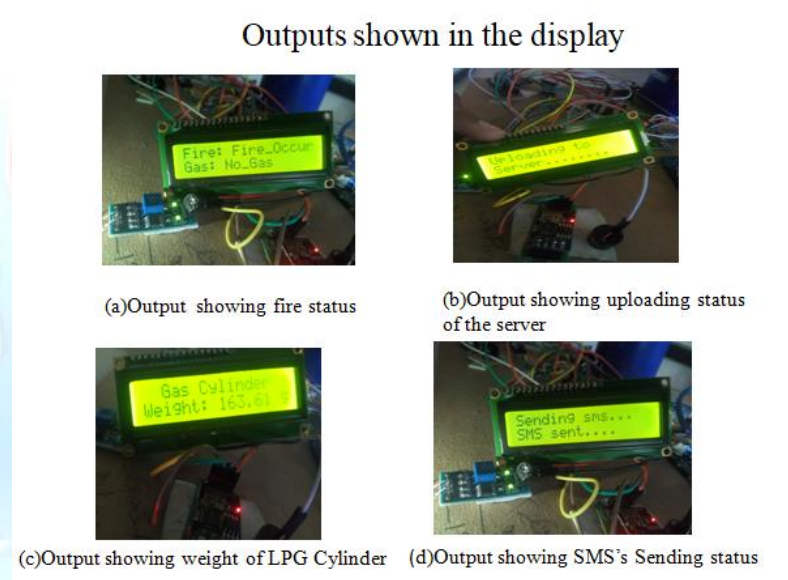

Outputs shown in the mobile and server
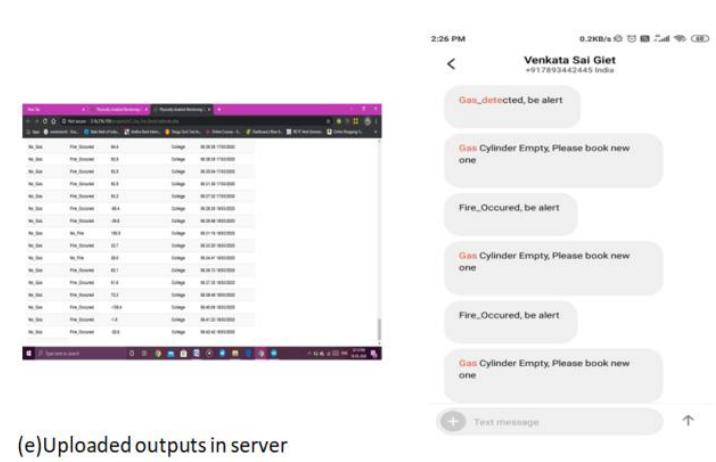

(e)Uploaded outputs in server

(f)SMS's sent to the user mobile

The above figure represents SMS messages in user mobile phone which is send by GSM module for different kinds of input reaction in our project. The message "Gas_detected be alert" is sent to the user when the LPG gas leaks. The message Gas 
Cylinder is Empty, Please book now" is sent to the user when LPG gas fully empty.

\section{Conclusion}

As we shorted out the problems faced by LPG gas consumers so we come up with some solutions to meet the few requirements of them, as we made our system is completely automate the process of refill booking without human intervention. Our system is also reasoned to help customers to upgrade their safety norms, act in accordingly with minimum requirements on environmental issues and mostly the basic function being prevented by major disasters and protect life and property from reputed Accidents. The primary objective of our project is to measure the gas present in the cylinder when weight of the cylinder is below the fixed load, this can be done using the weight sensors. The gas retailer gets the order for a new cylinder and the house owner (consumer) receives the message regarding the status and the secondary objective is to provide any malfunction in gas servicing system in order to prevent damage or explosion of LPG. Thus the system developed by us will somehow help the LPG Gas Consumers to lead a comfortable life.

\section{Future Scope:}

This monitoring system can be further enhanced by using Bluetooth in place of GSM to send the alert messages to user, which supports the another real-time application. For industrial purposes mobile robot can be developed for detecting multiple gas concentrations. Addition of load cell can also be used as pressure sensor which detects the amount of gas in the cylinder and also detects high pressure gas in cylinder pipe, displaying the alert messages via SMS and LCD displays.

\section{REFERENCES}

[1] Abhishek, P. Bharath, "Automation of lpg cylinder booking and leakge monitoring system," International Journal of Combined Research and Development (IJCRD), pp. 693-695, 2016.

[2] D. H. Priya and L. Babu, "Gas leakage system," International Journal of Scientific and Research Publications, p. 653, 2014.

[3] P. M. Vidya, S. Abinaya, G. G. Rajeswari, and N. Guna, "Automatic lpg leakage detection and hazard prevention for home security," in Proceeding of 5th National Conference on VLSI, Embedded and Communication \& Networks on April, vol. 7, 2014.

[4] K. Galatsis, W. Woldarsla, Y.X. Li and K. Kalantar-zadeh, "A Vehicle air quality monitor using gas sensors for improved safety", report in Recent Researches in Applications of Electrical and Computer Engineering.

[5] K. Galatsis, W. Wlodarsla, K. Kalantar-Zadeh and A. Trinchi, "Investigation of gas sensors for vehicle cabin air quality monitoring", National Conference on Synergetic Trends in engineering and Technology (STET-2014), International Journal of Engineering and Technical Research ISSN: 2321-0869

[6] "Smart Gas Cylinder Using Embedded System", Issn (Online) 2321 - 2004 Issn (Print) 2321 - 5526, International Journal Of Innovative Research In Electrical, Electronics, Instrumentation And Control Engineering Vol. 2, Issue 2, February 2014

[7] "Design and Implementation of an Economic Gas Leakage Detector" A. MAHALINGAM, R. T. NAAYAGI,1, N. E. MASTORAKIS§ Department of Engineering Systemsschool of Engineering, University of Greenwich (Medway Campus)Chatham Maritime, Kent ME4 4TBUNITED KINGDOM, article in Recent Researches in Applications of Electrical and Computer Engineering.

[8] Fraiwan, L.; Lweesy, K.; Bani-Salma, A.; Mani, N, "A wireless home safety gas leakage detection system", Proc. of 1st Middle East Conference on Biomedical Engineering, pp. 11-14, 2011.

[9] Johansson, A.; Birk, W.; Medvedev, A., "Model-based gas leakage Detection and isolation in a pressurized system via Laguerre spectrum analysis", Proc. of IEEE International Conference on Control Applications, pp. 212-216, 1998.

[10] Lopes dos Santos, P.; Azevedo-Perdicoúlis, T.- P.; Ramos, J.A.; Jank, G.; Martins de Carvalho, J.L.; Milhinhos, J., "Gas pipelines LPV modeling and identification for leakage detection", Proc. of American Control Conference, pp. 1211-1216, 2010.

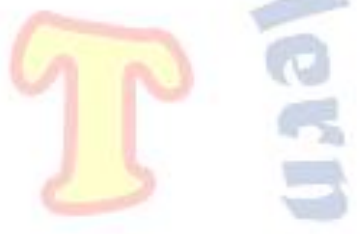

